The research program of the Center for Economic Studies (CES) produces a wide range of theoretical and empirical economic analyses that serve to improve the statistical programs of the U.S. Bureau of the Census. Many of these analyses take the form of CES research papers. The papers are intended to make the results of CES research available to economists and other interested parties in order to encourage discussion and obtain suggestions for revision before publication. The papers are unofficial and have not undergone the review accorded official Census Bureau publications. The opinions and conclusions expressed in the papers are those of the authors and do not necessarily represent those of the U.S. Bureau of the Census. Republication in whole or part must be cleared with the authors.

\title{
ESTIMATING THE HIDDEN COSTS OF ENVIRONMENTAL REGULATION
}

\author{
by \\ Satish Joshi* \\ Michigan State University \\ Ranjani Krishnan* \\ Michigan State University \\ and \\ Lester Lave* \\ Carnegie Mellon University \\ CES 02-10 May， 2002
}

All papers are screened to ensure that they do not disclose confidential information. Persons who wish to obtain a copy of the paper, submit comments about the paper, or obtain general information about the series should contact Sang V. Nguyen, Editor, Discussion Papers, Center for Economic Studies, Washington Plaza II, Room 206, $\overline{\text { Bureau }}$ of the Census, Washington, DC 20233-6300, (301-457-1882) or INTERNET address snguyen@ces.census.gov. 


\begin{abstract}
This paper examines whether accounting systems identify all the costs of environmental regulation. We estimate the relation between the "visible" cost of regulatory compliance, i.e., costs that are correctly classified in firms' accounting systems, and "hidden" costs i.e., costs that are embedded in other accounts. We use plant-level data from 55 steel mills to estimate hidden costs, and we follow up with structured interviews of corporate-level managers and plant-level accountants. Empirical results show that a $\$ 1$ increase in the visible cost of environmental regulation is associated with an increase in total cost (at the margin) of \$10-11, of which \$9-10 are hidden in other accounts. The findings suggest that inappropriate identification and accumulation of the costs of environmental compliance are likely to lead to distorted costs in firms subject to environmental regulation.
\end{abstract}

Key Words: Costing systems, hidden costs, environmental regulation, environmental management.

*Research results and conclusions expressed are those of the authors and do not indicate concurrence by the U.S. Census Bureau or the Center for Economic Studies. We thank the staff at the Center for Economic Studies for their support. Financial support for this research was provided by the Alfred P. Sloan Foundation. We thank Ken Cavalluzzo, Elizabeth Connors, Mark Epstein, Joan Luft, Francis McMichael, Nandu Nagarajan, Kathy Petroni, Mike Shields, Jhih-Shyang Shih, and workshop participants at the 2000 Annual American Accounting Association Conference, 1999 Big 10+ Accounting Research Conference, Carnegie Mellon University, and Georgetown University for their comments. We are grateful to the managers of the steel firms who participated in our study. 


\section{ESTIMATING THE HIDDEN COSTS OF ENVIRONMENTAL REGULATION}

\section{INTRODUCTION}

Compliance with environmental regulations can significantly affect product costs in industries such as chemicals, paper, steel, and utilities that face stringent environmental regulations. This paper examines how environmental regulations affect product cost in the U.S. steel industry. The steel industry suffered a major decline from 1974 to 1995, with production falling by 58 percent. The industry blamed environmental regulations as a major reason for the

decline. ${ }^{1}$ However the reported costs of environmental compliance constituted less than 5 percent of the cost of steel making, raising the question whether the reported environmental costs reflect the full impact of regulations. We examine if the costs identified in the accounting records as environmental costs capture all the environmental costs or if there are "hidden" costs associated with regulation that the accounting system does not identify. We estimate the magnitude of these hidden costs and explore their managerial implications. Our study provides a model that managers can use to estimate marginal costs of regulation including hidden costs, and to make cost-benefit tradeoffs of developing more detailed accounting systems to identify and manage these costs.

Environmental regulations affect firms' costs in several ways (White et al. 1995). Typical accounting systems easily identify and hence separately capture and accumulate "visible" cost of environmental compliance, such as installation and maintenance of pollution-control equipment and end-of-pipe emission treatment costs. Regulations also affect costs indirectly, by imposing additional constraints on firm production technology. For example, environmental compliance may require firms to substitute less polluting inputs for more polluting inputs, or to change the 
production process to limit emissions. Accounting systems often fail to identify separately the incremental costs of such changes, and instead include them in other cost pools. These hidden costs can be quite large, distorting the costs reported by the firm's costing system. ${ }^{2}$ Regulations can also lead to external costs to society for which firms are not currently accountable but which may become material in the long run, such as contingent environmental liabilities for Superfund sites and toxic releases.

Prior accounting research has concluded that contingent environmental costs affect firm value (Barth and McNichols 1994; Blacconiere and Patten 1994; Blacconiere and Northcut 1997; Hughes 2000), but has generally not empirically examined whether firms' managerial accounting systems accurately identify all the internal costs of environmental regulation. Two exceptions are case studies by Epstein (1996) and World Resources Institute (Ditz et al. 1995). Epstein's subjective judgment, based on telephone interviews and site visits, is that most firms do not adequately identify and measure all environmental costs. Ditz et al. use account analysis and reclassify components of product cost as environmental costs. They found substantial hidden costs of environmental regulations for select products in nine firms. However, they do not estimate the extent of hidden costs in the overall accounting system at the plant level.

We draw on unique, confidential, plant-level data from 55 steel mills from 1979-1988, to study the visible and hidden costs of environmental regulations in the U.S. steel industry. We use a cost function to estimate the hidden costs of regulation. Unlike most of the accounting literature examining production costs, which assumes simpler and more restrictive forms of production technology, we use a translog cost function. The translog is a flexible functional form that does not impose a priori restrictions on scale economies or substitution of inputs in response 
to changes in relative input prices, technology, and regulation. We estimate a system of structural equations that incorporate many cost drivers, including production volume, input prices, technology, regulation, and their interactions. We develop separate estimations for: (1) integrated mills, which produce steel from basic iron ore, and (2) mini-mills, which produce steel by recycling scrap.

The results indicate that visible costs, as reported by these firms' accounting systems, identify only a minor portion of the overall costs associated with regulatory compliance. For firms in the integrated mill sector, a $\$ 1$ increase in visible environmental operating expenditure is associated with an increase of $\$ 9.23$ in total cost (at the margin), of which $\$ 8.23$ is hidden, and embedded in accounts other than "regulatory costs." Similarly, for firms in the mini-mill sector, an increase of $\$ 1$ in the visible environmental operating expenditure is associated with an increase in total cost of $\$ 10.68$ (at the margin), of which $\$ 9.68$ is hidden. Thus, considering only the visible costs of environmental regulation will seriously under estimate the effect of regulation on cost and profit.

We also conducted structured interviews with corporate-level executives and plant-level accountants from seven steel firms to validate our econometric estimations and to gain insight into such questions as: are the managers aware of the large hidden costs of environmental regulation? What are the reasons for the large hidden costs? What types of decisions are large hidden costs likely to affect? We found that the managers are aware of these hidden costs but seriously underestimate their magnitude. The managers cited several reasons why the accounting system does not identify all environmental costs: difficulty in separating the environmental portion of the incremental costs of materials, utilities, and overheads; problems of aggregation 
across plants and functional departments; and complexity in separating environmental component of costs of process changes that have multiple objectives.

Our finding that the steel industry suffers from large hidden costs has implications for the design of costing systems in industries facing significant environmental regulations. Gross under-estimation of hidden costs is likely to lead to sub-optimal decisions in managing these costs. Hidden costs may distort variance analysis, contribute to product mis-pricing, and lead to inappropriate product mix, plant closure, and investment decisions. Our interviews reveal examples of these effects. We conclude that managers have under-estimated the magnitude of hidden costs, and our results suggest that they should reconsider the costs and benefits of updating standard costing systems to better track environmental costs.

The remainder of this paper is organized as follows. Section II discusses the effects of environmental regulations on firms' costs. Section III presents the estimation model; Section IV describes the data and variables; Section V discusses the results; and Section VI concludes.

\section{BACKGROUND}

\section{Visible and Hidden Costs of Environmental Regulation}

The total current costs of environmental regulations are the sum of visible costs, which the accounting system easily identifies and separately tracks, and hidden costs, which the accounting system does not directly identify. Visible costs include costs of installing and operating equipment to treat released pollutants, costs of wastewater treatment, and costs of treating and disposing of hazardous solid waste. Most accounting systems accumulate visible costs into environmental cost pools, separate from other overhead cost pools. Our interviews 
revealed for example, that many steel firms compile separate cost pools for waste water treatment, remediation, hazardous waste disposal, pollution abatement capital expenditures, and depreciation on pollution abatement equipment.

In addition to the visible costs of regulatory compliance, environmental regulations indirectly affect firms' costs by imposing other constraints on production processes, altering raw material compositions, input proportions, and energy use. For example, most integrated mills changed their raw material from sinters to less polluting pellets in response to more stringent regulation of the sintering process. Because the accounting system does not separately report the change in raw material cost as an environmental cost, these incremental costs due to the regulatory change are hidden within material costs. Similarly, when coke-oven emission standards became very strict, steel firms reduced coke consumption by injecting natural gas and pulverized coal into their blast furnaces. As a result, firms reduced their average coke rate (i.e., tons of coke used per ton of raw steel produced) from 0.64 in 1975 to 0.45 in 1994, while increasing the use of other fuels. Many mills replaced coal with natural gas or electricity in their boilers and furnaces in response to the air quality regulations. The incremental costs of these changes are hidden under energy cost or factory overhead costs. Firms incur additional indirect labor costs to monitor and report emissions, and to maintain pollution control equipment.

Environmental regulations can also increase general and administrative costs. For example, legal staff may be involved in regulatory activities such as obtaining permits, licenses, and so on. However, firms rarely report such costs as environmental costs, and instead include them in general and administrative overheads (Epstein 1996). Such hidden environmental costs cannot be completely attributed to specific transactions. Managers must use other methods to 
estimate hidden costs. Ditz et al. (1995) note that most firms' managerial accounting systems depend on discrete historical transactions and pooling of costs which can conceal and distort critical information on environmental and other costs.

Field studies suggest that most firms' costing systems fail to identify the full effect of regulation on cost. Epstein (1996) in an attempt to document best practices for identifying, measuring, monitoring and managing environmental costs, studied more than 100 companies. His field study concludes that most companies lack adequate systems for measuring and managing environmental costs; they do not separately track or accumulate environmental costs and most environmental costs are hidden in various overhead accounts. Hence most companies do not know the total costs of environmental regulation. However, Epstein (1996) does not provide evidence on the magnitude of hidden costs. Similarly, in Price Waterhouse's (1994) survey of 445 companies, $49 \%$ of the companies surveyed responded that their cost accounting systems do not identify all the costs of environmental compliance.

In 1993, the World Resource Institute (WRI) conducted nine case studies exploring how firms account for environmental costs (Ditz et al. 1995). The case-study firms included Amoco Oil, Ciba-Geigy, Dow Chemical, E.I. Du Pont de Nemours, and S.C. Johnson Wax. The studies are based on a review of cost and environmental information gathered through on-site interviews of corporate and plant-level personnel. The authors analyze cost data for one specific product line in each firm to illustrate environmental components in traditional product cost categories. For example, they separate the maintenance of pollution abatement equipment from total maintenance costs. The results indicate that total environmental cost for the selected product lines range from 2.5 percent of net sales for S.C. Johnson Wax to 22 percent of operating costs 
for Amoco Oil. The total environmental cost for Ciba-Geigy and Du Pont amounted to 19 percent of manufacturing cost. ${ }^{3}$ In all these firms, the cost accounting system identified only a portion of the total environmental cost as "environmental". Ditz et al. (1995) do not estimate the extent of hidden costs in the overall accounting system at the plant level, nor do they examine the effect of an increase in regulatory stringency on total cost.

Finally, economists have concluded that environmental regulations hurt the productivity growth rate in the steel industry (Barbera and McConnell 1990; Gray and Shedbegian 1993). ${ }^{4}$

\section{Cost of Environmental Regulation in the U.S. Steel Industry}

Prior to 1994, the U.S. Census Bureau collected data on environmental costs in the steel industry and other industries in the manufacturing sector, through an annual "MA-200, Pollution Abatement Costs and Expenditure (PACE)" survey. The PACE surveys contain information on pollution abatement capital and operating expenditures classified by pollution medium (air, water, and land) and by cost categories (labor, material, capital, and energy) at the individual plant level. (The Appendix contains further details on the purpose, content, and methods of the PACE surveys.)

The PACE surveys are the most comprehensive available estimates of firms' environmental costs. Title 13 of the US Code requires firms to respond to the PACE survey and to certify that the reports are substantially accurate. The data are to be based on company's accounting records and if accounting records are not available, carefully prepared estimates are acceptable. The reporting instructions further note that some of these estimates may require the joint efforts of the firms' financial and engineering staffs. In our interviews, steel firm managers 
indicated that the PACE survey data represent the best available internal cost data for environmental regulatory expenses. Managers of two large steel firms stated that they still use the PACE format to track environmental costs, although the Census Bureau no longer conducts these surveys. They also mentioned that most steel firms' environmental accounting systems are set up primarily to meet PACE reporting requirements. Furthermore, firms have no incentives to understate their environmental expenditures in PACE reports, especially when the steel industry has blamed environmental regulations for its decline.

The PACE data indicate that the environmental capital expenditures for the entire U.S. steel industry range from a low of \$0.67/Short Ton (ShT) of steel produced in 1988 to a high of about $\$ 6.36 /$ ShT in 1980 (Table 1). Environmental operating expense ranges from a low of $\$ 4.95 /$ ShT in 1975 to a high of $\$ 13.84 /$ ShT of steel produced in 1982 . Total reported cost of environmental regulation has ranged from $\$ 8.86 /$ ShT in 1988 to $\$ 18.94 /$ ShT in 1980 .

\section{[TABLE 1 HERE]}

Although the number of environmental regulations and their stringency have increased over time, the reported cost of environmental regulations shown in Table 1 does not increase monotonically. Some of the reasons include: (a) minimills which have relatively low

environmental costs, increased their share of U.S. raw steel output from 17 percent to 39 percent between 1973 and 1991; (b) the closure of several mills and process units (such as sintering plants, beehive coke ovens, and open-hearth furnaces) with high compliance costs; and (c) improvement in pollution abatement technology. Furthermore, most mills could not comply immediately with many regulations (such as the Clean Air Act) and the steel firms negotiated consent decrees specifying both the time when the mill would come into compliance and the 
reductions it would achieve each year. Because all mills are not required to meet a specific regulation on a specific date, and because each steel mill found its own way to change processes to comply with the regulations, the visible costs of regulation do not increase uniformly. Table 1 also shows that the cost/ton of production capacity (which purges variations simply due to changes in capacity utilization) reveals a similar pattern. ${ }^{5}$

The reported cost of compliance with environmental regulation shown in Table 1 represents less than 5 percent of the total cost of steel production, which is clearly insufficient to explain the crisis in the industry. However, findings from earlier accounting and economic studies (Epstein 1996; Ditz et al.1995; Barbera and McConnell 1990; Gray and Shadbegian 1993), and the claims of the steel industry that environmental regulations are a major reason for its decline, suggest that these reported costs may understate the true costs of regulation.

To study the hidden costs of regulation, we use a unique plant-level panel data set for the steel industry that draws on various confidential databases of the U.S. Census Bureau. We assume an economic model of production, where firms minimize cost, subject to the chosen output level, input prices, and regulatory restrictions. We estimate translog restricted cost functions with the visible pollution abatement operating expenditures as an index of quasi-fixed regulatory restriction. The parameters of the estimated cost function reveal the magnitude of the hidden costs of environmental regulation. We also estimate the extent of hidden costs in different cost pools. We follow up with interviews of steel firm managers to validate the results, identify the reasons for the hidden costs, and discuss managerial implications. 


\section{MODEL OF PRODUCTION UNDER ENVIRONMENTAL REGULATIONS}

We base our model on a standard, restricted cost function for production. We assume that firms minimize steel production cost (C) for given input prices, output volume, technology, and regulatory stringency. That is, the cost function of steel production is of the following form: ${ }^{6}$

$$
C=C\left(P_{L}, P_{M}, P_{E}, P_{K}, Y, T, R\right)
$$

where, $P_{L}, P_{M}, P_{E}$, and $P_{K}$ are exogenously determined prices of input factors, labor, materials, energy, and capital, respectively. $Y$ represents the firm's output. $T$ is a time trend variable representing technological change. $R$ represents environmental regulatory restriction, which acts as an exogenous, quasi-fixed restriction on the production technology that causes a firm to change its combination of conventional inputs to produce output.

We assume that factor markets are competitive. By the mid-1970s, steel mills had divested most of their mining operations, and strong international markets had emerged for commodities such as iron ore, ore concentrates, bituminous coal, and coke. Similarly, market prices for scrap and electricity used by minimills are exogenous, because the number of minimills and suppliers of these factors is large. We assume $\mathrm{R}$ is exogenous because the regulations affecting the steel industry are technology-based standards that often contain detailed specifications on the control equipment. For example, the Clean Air Act required existing plants to install abatement equipment with "reasonably available control technology," and new plants to install "lowest achievable emission rate technology" as specified by USEPA.

The elasticity of total cost with respect to change in regulatory restriction (i.e., the percent change in total cost for 1 percent change in the regulatory restriction) is given by the partial derivative $\partial \ln C / \partial \ln R$. Our model uses the reported, visible environmental operating 
expenditure per unit output as a comprehensive measure of environmental regulatory restriction, $R$. (Section IV details the reasons for choosing this measure). If environmental regulations have no associated hidden effects, then a $\$ 1$ increase in the reported environmental costs should increase the total costs by $\$ 1$. In other words, the estimated value of the regulatory elasticity, $\partial \ln C / \partial \ln R$, should equal the average share of reported environmental expenditure in total product costs. If there are hidden costs not captured by the reported environmental costs, then total costs will increase by more than $\$ 1$ (i.e. the estimated $\partial \ln C / \partial \ln R$ will be larger than the share of reported environmental expenditure in total product costs). The estimated regulatory elasticity reveals the extent of hidden costs. ${ }^{7}$

To operationalize the model, we must choose a functional form and then estimate the cost function. Prior empirical accounting studies typically assume a simple linear relation between product cost and volume of output, input prices, and other cost drivers. For example, Banker and Johnston's (1993) study of the airline industry assumes a Leontief-type production function that does not allow substitution among inputs. They argue that a Leontief production function is justified because of limited substitution among inputs in the air-transportation services industry. However, their model also ignores economies of scale in the determination of the overall cost. Steel firms are likely to substitute away from inputs that become more expensive due to changes in relative prices. Steel production technology also exhibits economies of scale, making the relation between total cost and volume nonlinear. Thus, we use a translog cost function, which allows economies of scale, substitutions in response to input price changes, substitution of inputs in response to regulation (i.e., substitution towards less polluting inputs), and interactions between inputs and output volume. The translog function is a second-order Taylor series 
approximation of an arbitrary cost function (Christensen et al. 1973). Translog is a flexible functional form, which does not impose any a priori restrictions on substitution elasticities or scale economies. Simulation analyses have found that the translog cost function outperforms other flexible functional forms in approximating real underlying production technology (Guilkey et al. 1983). We also improve the efficiency of parameter estimation by estimating the translog cost function along with the cost-share equations as a system of equations. ${ }^{8,9}$

The translog cost function has the form:

$$
\begin{aligned}
C=\exp & \left(\beta_{0}+\sum_{i} \beta_{i} \ln P_{i}+\beta_{Y} \ln Y+\beta_{T} T+\beta_{R} \ln R+\frac{1}{2} \sum_{i} \sum_{j} \gamma_{i j} \ln P_{i} \ln P_{j}\right. \\
& +\sum_{i} \gamma_{i Y} \ln P_{i} \ln Y+\sum_{i} \gamma_{i T} \ln P_{i} T+\sum_{i} \gamma_{i R} \ln P_{i} \ln R+\frac{1}{2} \gamma_{Y Y}(\ln Y)^{2} \\
& \left.+\gamma_{Y T} \ln Y T+\gamma_{Y R} \ln Y \ln R+\frac{1}{2} \gamma_{T T} T^{2}+\gamma_{T R} T \ln R+\frac{1}{2} \gamma_{R R}(\ln R)^{2}\right)
\end{aligned}
$$

where $i, j \in(L, M, E, K)$

We impose the following linear homogeneity constraints:

$$
\begin{aligned}
& \beta_{L}+\beta_{M}+\beta_{E}+\beta_{K}=1 \\
& \Sigma_{i} \gamma_{i j}=0 \\
& \Sigma_{j} \gamma_{i j}=0
\end{aligned}
$$

The restrictions of linear homogeneity in input prices assure that when prices of all the inputs increase by a fixed percent, holding all else constant, total cost also increases by the same percent.

We also impose the symmetry conditions $\gamma_{i j}=\gamma_{j i}$ 
By Shephard's (1970) lemma, the cost-share $\left(\mathrm{S}_{\mathrm{i}}\right)$ of input $i$ equals the partial derivative $\partial \ln C / \partial \ln P_{i}$. Hence, we express the cost shares of labor $\left(\mathrm{S}_{\mathrm{L}}\right)$, materials $\left(\mathrm{S}_{\mathrm{M}}\right)$, energy $\left(\mathrm{S}_{\mathrm{E}}\right)$, and capital $\left(\mathrm{S}_{\mathrm{K}}\right)$ as:

$$
\begin{aligned}
& S_{L}=\beta_{L}+\sum_{j} \gamma_{L j} \ln P_{j}+\gamma_{L Y} \ln Y+\gamma_{L T} T+\gamma_{L R} \ln R \\
& S_{M}=\beta_{M}+\sum_{j} \gamma_{M j} \ln P_{j}+\gamma_{M Y} \ln Y+\gamma_{M T} T+\gamma_{M R} \ln R \\
& S_{E}=\beta_{E}+\sum_{j} \gamma_{E j} \ln P_{j}+\gamma_{E Y} \ln Y+\gamma_{E T} T+\gamma_{E R} \ln R \\
& S_{K}=\beta_{K}+\sum_{j} \gamma_{K j} \ln P_{j}+\gamma_{K Y} \ln Y+\gamma_{K T} T+\gamma_{K R} \ln R
\end{aligned}
$$

We obtain the marginal effect of regulation on cost by the partial derivative $\partial \ln C / \partial \ln R$,

where

$$
\frac{\partial \ln C}{\partial \ln R}=\beta_{R}+\underset{i}{\sum} \gamma_{i R} \ln P i^{+} \gamma_{Y R} \ln Y+\gamma_{T R} T+\gamma_{R R} \ln R
$$

If the hypothesis that $\partial \ln C / \partial \ln R=0$ cannot be rejected, then regulations have no effect on production costs. The parameter restrictions to test this hypothesis are

$$
\beta_{R}=\gamma_{L R}=\gamma_{M R}=\gamma_{E R}=\gamma_{K R}=\gamma_{Y R}=\gamma_{T R}=\gamma_{R R}=0
$$

A positive value of $\partial \ln C / \partial \ln R$ indicates that regulation increases production cost, and conversely.

The values of the parameters $\gamma_{\mathrm{LR}}, \gamma_{\mathrm{MR}}, \gamma_{\mathrm{ER}}$, and $\gamma_{\mathrm{KR}}$ reveal the effect of environmental regulations on various input cost shares. We partition the costs of regulation in various input cost categories using these coefficient estimates.

We estimate the cost function in equation (2) and the four factor share equations (7) through (10) as a system of seemingly unrelated regression equations (SURE), by adding a 
stochastic disturbance term to each equation (Greene 1993, 526-531; Berndt 1996, 469-487). The error terms are correlated across equations because the cost shares must sum to one. SURE estimation improves the efficiency of parameter estimates when cross-equation errors are correlated. To overcome singularity of the covariance matrix (because the cost shares sum to one), we normalize the total cost and prices by the price of capital and delete the capital share equation. We use maximum likelihood procedures to estimate the resulting system, and perform separate estimations for the integrated mills and mini-mill samples.

\section{DATA}

Plant level data on input prices, input quantities, output, and the regulatory expenditure are from the Census of Manufacturers (CM), Annual Survey of Manufacturers (ASM), Manufacturing Energy Consumption Survey (MECS), and PACE surveys available at the Bureau of the Census. ${ }^{10}$ We use data from 55 steel mills, covering the period 1979 to $1988 .{ }^{11}$ We limit our sample to mills for which data on all variables are available. The final sample consists of 109 observations for 29 mini-mill plants (belonging to 27 mini-mill firms), and 94 observations for 26 integrated steel plants (belonging to 16 integrated steel firms), covering the years 1979, 1980, 1981, 1985, and 1988. During the period of our study, a total of 89 mini-mill firms and 17 integrated mill firms operated in the U.S. steel industry. Hence, our study covers almost the entire population of integrated mill firms. Our coverage of mini-mills is less complete because MECS and ASM databases cover only a random sample of mini-mills.

The following sub-sections describe how we construct the variables used to estimate the cost function. 
Price of Labor $\left(\boldsymbol{P}_{L}\right)$ : The price of labor is the average cost per employee, including salaries, wages, and benefits. Data on the total number of employees and total labor costs are from the Annual Survey of Manufacturers and Census of Manufacturers databases.

Price of Materials $\left(\boldsymbol{P}_{M}\right)$ : Steel firms use numerous types of direct materials to produce steel. Coal, coke, scrap, ingots, ores, and agglomerates (pellets and sinter) account for about 85 percent of total material costs. Annual data on total materials and parts expenditures are available in Annual Survey of Manufacturers. However, only Census of Manufacturers, conducted once every five years, collects data on quantities in addition to expenditures on individual materials. We derive a composite divisia index of material price for each individual plant using the data on the previously mentioned seven materials for the years 1977,1982 , and $1987 .^{12}$ A simple, linear interpolation of individual plant material price indices yielded the price indices for the intervening years. However, we use the actual total expenditures on materials and parts to calculate material cost shares in our estimation.

Price of Energy $\left(\boldsymbol{P}_{\boldsymbol{E}}\right)$ : The steel-making process consumes various types of energy, such as natural gas, electricity, distillate fuel oil, residual fuel oil, and liquid petroleum gas. Plantlevel fuel consumption and expenditure data are from Manufacturing Energy Consumption Survey for 1985 and 1988, and special energy consumption surveys conducted by the Bureau of the Census prior to 1985 . We calculate the prices of individual fuels in \$/million British thermal units (Mbtu) of energy paid by each plant, and derive an aggregate divisia energy price index for individual mills using the fuel cost shares.

Price of Capital $\left(\boldsymbol{P}_{\boldsymbol{K}}\right)$ : We use the Hall-Jorgenson (1967) procedure to calculate the service price of capital. Hence,

$$
P_{K(t)}=\left[q_{t-1} r_{t}+\delta q_{t}-\left(q_{t}-q_{t-1}\right)+q_{t} X_{t}\right] \frac{1-u_{t} z_{t}-k_{t}}{1-u_{t}}
$$


Where:

$P_{K(t)}=$ Service price of capital,

$q_{t}=$ Price index of new capital equipment,

$r_{t}=$ After-tax risk-adjusted rate of return on capital (opportunity cost),

$\delta=$ Rate of economic depreciation,

$X_{t}=$ Effective property tax rate,

$u_{t}=$ Effective corporate income tax rate,

$z_{t} \quad=$ Present value of allowed depreciation tax deductions on a dollar's investment over the life time of an asset,

$k_{t} \quad=$ Investment tax credit,

$t=$ Year.

This service price of capital compensates the owner of assets for the real opportunity cost of capital ( $r$ ) and economic depreciation of the asset( $\delta$ ), after adjusting for capital appreciation due to asset price changes $\left(q_{t}-q_{t-1}\right)$ and the tax effects. The capital stock price indices for the steel industry are from Gray (1987) and have been updated. We use the average after-tax yield to maturity of the bonds issued by the parent company as a plant's risk-adjusted opportunity cost of capital. Whenever bond data were not available for a particular firm, we use the average yield on Moody's "Baa" bonds for the integrated mills, and the yield on " $A$ " bonds for the minimills. This reflects the relatively lower risk of mini-mills during this period. The economic depreciation rates are from Hulten and Wykoff (1981). The tax rate information is from Jorgenson and Yun (1991) and Jorgenson and Landau (1993).

Capital Stock: We use the perpetual inventory method proposed by Christensen and Jorgenson (1969) to estimate the real capital stock. ${ }^{13}$ Using data on capital additions and retirements from the Annual Survey of Manufacturers database, we constructed a real capital stock series for the period 1972 to 1989. 
Output (Y): A typical steel mill produces a wide variety of products. In the Annual Survey of Manufacturers, steel mills report 95 separate product classes. However, nine product classes account for about 95 percent of the total value of shipments. ${ }^{14} \mathrm{We}$ weight the quantities (in short tons) of products by the average relative sales price of the product and then sum to construct a single composite output quantity index. For example, if the average price of hot rolled steel sheet is $\$ 300 / \mathrm{ShT}$ and the average price of cold rolled steel sheet is $\$ 330 / \mathrm{ShT}$, then one ShT of cold rolled steel is considered equivalent to $1.1 \mathrm{ShT}$ of hot rolled steel in our output measure. ${ }^{15}$ Average prices for each product class are from the annual Current Industrial Reports (CIR). Relative prices are with respect to the price of hot rolled sheets and strip.

Time (T): Time $T$ is a trend variable that allows for technological progress over the years. The value of $T$ for year 1983 is set at zero, so $T$ equals -4 in 1979, and 5 in 1988.

Regulation $(\boldsymbol{R})$ : A measure of regulatory stringency is ideally a specific constraint on the production process, such as the emission limit on a particular pollutant. However, steel mills must comply with a large number of process-specific technology standards and emission limits, and the timetables for meeting different standards on process units vary. For example, the national emissions standards for hazardous air pollutants specify separate emission limits for six emission points on a coke oven. Firms can choose among four compliance tracks, each of which provides interim emission limits and the dates by which the firms must meet them (USITC, 1994). But, many steel plants negotiated individual "stretch-out" compliance time tables with the EPA and State agencies based on their financial situations, investment needs, and union pressures (Landy et al. 1990). Because it is very difficult to operationalize regulatory stringency in terms of specific constraints on the production process, we use annual pollution-abatement 
operating expenditures (including the depreciation on the pollutio- abatement capital) as a comprehensive measure of regulatory intensity. Environmental expenditures provide a reasonable proxy for regulatory pressure by aggregating realized effects of emission standards, legal and political battles, technical negotiations, enforcement effort, and innovation. Using environmental operating expenditures as the measure of regulatory intensity also allows a straightforward interpretation of the estimated elasticity of total costs with respect to regulation.

Data on plant-level annual operating expenditures on pollution abatement are from the PACE surveys. We normalize the total expenditures by the plant output index to control for plant size.

Total Cost $(\boldsymbol{C})$ : The dependent variable, total cost, is the sum of total expenditures on labor, total materials cost, total expenditures on fuels and electricity, and capital cost measured as the product of real capital stock and the service price of capital described by equation (13).

\section{RESULTS}

\section{Results from the cost function estimation}

Parameter estimates for the translog cost functions for the integrated mills and the minimills appear in Tables 2 and 3, respectively. ${ }^{16}$ Overall, the regressions are highly significant. The tables report estimates of all the coefficients in the system of equations. The individual coefficients, which estimate the first-order and second-order slopes of the cost function in the input-price, output, time, and regulation dimensions, have limited direct interpretation value. We focus on the coefficients related to the effects of regulation on cost since our primary interest is in estimating the hidden costs of regulation. (The other coefficients are useful for calculating 
substitution elasticities among various inputs, conditional input factor demand equations, scale effects, and the productivity growth rate.)

\section{[TABLES 2 AND 3 HERE]}

The elasticity of total cost with respect to regulation, evaluated at the means of the variables using equation (11), appears in Table 4 (Row 3). The elasticity estimates are positive, indicating that regulation is associated with higher total costs. The likelihood ratio test rejects the null hypothesis that there are no effects of environmental regulation on costs - that is, that $\partial \ln C / \partial \ln R=0$ - for both the integrated mills $\left(\chi^{2}=43.44, \mathrm{p}<0.01\right)$ and the mini-mills $\left(\chi^{2}=72.69\right.$,

$\mathrm{p}<0.01$ ). The estimated elasticities are 0.3079 for integrated mills and 0.2827 for mini-mills. ${ }^{17} \mathrm{~A}$ 1 percent increase in regulatory stringency from its average value (as measured by the reported environmental operating expenditure/ShT) is associated with a 0.3079 percent increase in total costs at the margin for integrated mills, and 0.2879 percent increase in costs for mini-mills.

\section{[TABLE 4 HERE]}

These regulatory elasticity estimates indicate that hidden costs are substantial. Consider an integrated mill with our sample-average production cost of \$360/ShT and reported environmental operating costs of $\$ 12 /$ ShT (Table 4). Any increase in regulatory stringency causing a \$1 increase in reported or "visible" environmental operating expenditures is associated with an increase in firms' total cost by $\$ 9.23$ at the margin. However, $\$ 8.23$ of the incremental cost of regulatory compliance is hidden under other (non-regulatory) accounts. Similarly, for a mini-mill with an average production cost of \$340/ShT and reported environmental operating expenditures of $\$ 9 / \mathrm{ShT}$, a $\$ 1$ increase in the visible portion of environmental regulation costs is associated with an increase in total cost by $\$ 10.68$ at the margin, of which $\$ 9.68$ is in the form of 
hidden costs accumulated under other accounts. Thus, hidden costs associated with environmental regulation far exceed the visible costs of pollution abatement. Tables 2 and 3 also show that $\gamma_{\mathrm{YR}}$ has a significant positive coefficient for both the sectors. This suggests that increased regulatory stringency is associated with reduced levels of scale economies.

These hidden costs are estimates at the margin. The current model does not estimate the average level of hidden costs. If the current average visible cost of environmental regulation in the steel industry is about $\$ 10 / \mathrm{ShT}$, the elasticity estimates do not mean that the average total environmental cost is $\$ 92$ to $\$ 117 /$ ShT. The average cost is likely to be less than the estimated marginal cost of regulation because it is relatively inexpensive to reduce emissions initially, and the marginal costs of emission abatement increase as stringency increases (i.e., the marginal cost curve is nonlinear and rising). However, the estimates indicate that increases in regulatory stringency from the current levels are likely to trigger large hidden costs.

\section{Other estimation issues}

The estimated cost functions are not guaranteed to satisfy properties of positive fitted cost shares and concavity in input prices required for proper cost functions. Concavity in input prices ensures that, when the price of one input increases, holding everything else constant, the total cost does not decrease and costs increase at a decreasing rate as firms shift away from the relatively more-expensive input. In our estimated cost functions, all the fitted cost shares were positive, and concavity conditions were satisfied at about 90 percent of the data points. ${ }^{18}$ Hence the estimated cost function satisfies the desired theoretical properties. 
Output quantity can be endogenous to the model. We test for endogeneity of output in the cost function using the omitted variable version of the Hausmann Test ${ }^{19}$ and reject the hypothesis that endogeneity bias exists for both the mini-mill and the integrated mill samples.

Inefficiency in estimation due to serial correlation is not likely to be a problem, because we have a relatively large number of plants and only a few time periods, and because gaps between the reporting years allow any serial correlation effects to fade. Also, because our estimation does not include lagged dependent variables, coefficient estimates are unbiased. ${ }^{20}$

The 55 plants in our sample represent 43 firms with no one firm contributing more than three sites. During our interviews, the managers of steel firms with multiple plants indicated that reporting for the PACE survey was decentralized at the plant level. Similarly, most of these steel firms' managerial accounting systems are decentralized. Hence common practices at the firm level do not significantly affect our estimates.

The estimated regulatory elasticity measures the variation in total costs associated with variations in the reported visible environmental costs, which does not establish causality. Firms may incur expenses that improve quality and worker safety as well as environmental performance. To the extent this bundling occurs, increases in total cost associated with an increase in the reported visible environmental cost may not be entirely attributable to regulation, thereby overstating hidden costs. Conversely, if firms bundle environmental expenditures with productivity improvement projects, the associated increase in total cost may underestimate regulatory effects. Our model estimates the net effect of any such bundled expenditures. However, statistical analysis using data from a large number of plants over many years is likely to distinguish between costs that vary systematically with visible environmental expenditures 
and costs that were associated temporarily. Finally, the steel firm managers we interviewed indicated that they generally did not systematically bundle other expenditures with environmental expenditures.

The model is based on contemporaneous variations in total and regulatory costs, and does not incorporate learning effects that may reduce hidden costs in subsequent periods.

\section{Extent of hidden costs in major cost pools}

In this section, we estimate the extent of hidden costs in different types of cost pools. These estimations use the mean values of costs and cost shares from either the integrated mill or mini-mill sample. The mean cost shares of the four major input cost pools, (i.e., labor, materials, energy, and capital) appear in Table 5. For example, the mean share of labor in the total cost of production is 28.8 percent for the integrated mills sector, and mean cost shares for materials, energy, and capital are 55.67 percent, 7.77 percent, and 7.76 percent respectively.

\section{[TABLE 5 HERE]}

A 1 percent increase in environmental operating costs has two effects, First, it is associated with an increase of 0.3079 percent in total costs for integrated mills and 0.2827 percent for mini-mills (Table 4). Second, for the integrated mills sector, it is also associated with a shift in the cost shares of each of the four inputs (labor, materials, energy, and capital) as indicated by the statistically significant parameter estimates for $\gamma_{\mathrm{LR}}, \gamma_{\mathrm{MR}}, \gamma_{\mathrm{ER}}$, and $\gamma_{\mathrm{KR}}$ in Table 2. Results suggest that for the integrated mills sector, a change in regulatory stringency that increases visible environmental operating costs by $\$ 1 / \mathrm{ShT}$ increases total costs by $\$ 9.23 / \mathrm{ShT}$

(per Tables 4 and 5), and changes the share of labor cost from 28.80 percent to 29.05 percent, $^{21}$ materials cost share from 55.67 percent to 55.26 percent, energy cost share from 7.77 percent to 
7.85 percent, and capital cost share from 7.76 percent to 7.84 percent. The negative parameter estimate for $\gamma_{\mathrm{MR}}$ implies that the share of materials cost in the total cost declines after the increase in regulatory stringency, consistent with steel mills' responding to more stringent regulations by using materials more efficiently and cutting waste. ${ }^{22}$

For the mini-mill sector, the parameter estimates of $\gamma_{\mathrm{LR}}, \gamma_{\mathrm{MR}}, \gamma_{\mathrm{ER}}$, and $\gamma_{\mathrm{KR}}$ are not statistically different from zero. This indicates that the cost shares of various inputs do not change significantly in response to an increase in regulatory stringency. Thus the cost shares of labor, materials, energy, and capital remain at 30.55 percent, 51.75 percent, 11.96 percent and 5.74 percent before and after an increase in regulatory stringency. Total cost however, increases from $\$ 340 /$ ShT to $\$ 350.68 /$ ShT in response to a $\$ 1 /$ ShT increase in the reported (visible) cost of environmental regulation.

Table 5 also reports the mean costs in various input cost pools before and after a $\$ 1 / \mathrm{ShT}$ increase in the reported (visible) cost of environmental regulations. The change in total cost less the visible portion of regulatory expenses indicates the costs associated with environmental regulation that are hidden in other cost pools. In estimating these hidden and visible costs, we assume that the visible cost shares of labor, material, energy and capital are the same as their respective shares of the total cost. For example, since labor costs are $29 \%$ of the total cost, we assume the labor cost share of the $\$ 1$ increase in visible regulatory cost is $\$ 0.29$. For the integrated mill sector, the increase in regulatory stringency is associated with a $\$ 3.58 / \mathrm{ShT}$ increase in labor cost, from $\$ 103.68 / \mathrm{ShT}$ to $\$ 107.26 / \mathrm{ShT}$. Of this $\$ 3.58$ increase, only $\$ 0.29$ is visible as an increase in regulatory labor costs. The remaining $\$ 3.29 /$ ShT remains hidden in other labor cost pools. Total materials cost increases by $\$ 3.63 /$ ShT (from $\$ 200.41 / \mathrm{ShT}$ to 
$\$ 204.04 / \mathrm{ShT}$ ) of which $\$ 0.55$ is in the form of visible environmental material costs and the remaining \$3.08/ShT is hidden in other materials accounts. Similarly, hidden costs for energy and capital are \$0.93/ShT each.

For the mini-mill sector, the labor cost increases from $\$ 103.87 / \mathrm{ShT}$ to $\$ 107.13 / \mathrm{ShT}$. Of this $\$ 3.26 /$ ShT increase, only $\$ 0.30$ is in the form of visible environment-related labor expenses. Environmental expenses hidden in other direct and indirect labor accounts amount to \$2.96/ShT. Similarly, \$5.01/ShT is hidden in materials cost accounts, $\$ 1.16 /$ ShT is hidden in energy costs and $\$ 0.55 / \mathrm{ShT}$ is hidden in various capital cost pools.

\section{Results from telephone interviews}

Our hidden cost estimates are high. Hence, we conducted in-depth telephone interviews with steel firm managers to explore the validity of the econometric estimations and to gain insight into the following questions: First, do the PACE survey data reasonably represent the data from steel firms' internal management accounting systems? Second, are managers aware of the large hidden costs associated with environmental regulation? Third, what are the reasons for the large hidden costs? Do plant managers exercise discretion over reporting in the PACE surveys? Does the failure to include all costs associated with environmental regulations reflect managerial choices, ignorance, or a belief that a cost does not represent a regulatory cost even if it is associated with environmental regulation? Finally, what types of decisions are large hidden costs likely to be affect?

We contacted senior-level managers of several integrated mills and mini-mills. We interviewed executives from a total of seven firms, which together account for about 40 percent

of the total domestic U.S. steel production. ${ }^{23}$ In some firms we were able to interview plant-level 
accountants in addition to corporate-level managers. The individual interviews lasted up to two hours.

All the managers agreed that the PACE survey data were a good representation of the internal accounting systems' environmental cost data. One manager stated that "...the PACE reports are our best available numbers. A lot of care is taken in obtaining these numbers. We still use the PACE survey format to keep track of environmental costs, although they are no longer required by the Census Bureau."

All managers were aware that the visible costs reported in PACE surveys and internal accounting systems fell short of the total cost of environmental regulation. One manager estimated that the total cost per ton of environmental regulations, including the hidden costs, could be as high as roughly $\$ 40$ per ton. This is about four times the average reported environmental costs for the year 1998 for our sample firms that reported environmental costs in their 10-K statements. Another manager said he would not be surprised if the hidden costs were very large. Other managers' initial estimates of total costs were lower at 130 percent 200 percent of reported costs. However, when we asked if they had considered costs of input substitutions, process changes, and other specific examples of hidden costs of regulation, most had not, and as result became less certain of their initial estimates.

The managers discussed several reasons for not reporting the hidden costs. It is often difficult to isolate the extent to which costs (such as process changes) are attributable to environmental regulation rather than other productivity-improvement initiatives. One manager mentioned continuous casting, which has quality and productivity benefits in addition to environmental benefits. It would be difficult to isolate the environmental portion of the total cost 
of converting to continuous casting. Similarly, overhead costs (such as utility costs) may have several drivers. One firm reported difficulty separating the electricity costs of different environmental processes and equipment because the firm used one common electricity meter. Further, environmental control components are an integral part of most modern process equipment, making the separation of environmental costs difficult. We also asked whether the firm's accounting system reported incremental costs of switching from sinters to pellets and other such input substitutions as environmental costs. All the managers agreed that their systems would not report these as environmental costs but would instead include them in general material costs. Similarly, these firms did not separately track incremental costs of environmental training, reporting, permitting, and legal expenses. Managers also referred to difficulty aggregating across plants and functional areas. Most of the multi-plant firms' costing systems are decentralized to the plant level. The operations/production department maintains some cost records while the purchasing department maintains others. Detailed analysis, decomposition, and allocation of environmental costs requires both technical and accounting expertise. Departments often failed to communicate while preparing these reports.

Technical staff at the plant level made input substitutions and changes in process parameters to meet emission limits, based on ad hoc cost analysis. However, changes were often not made to the formal cost accounting system to incorporate the incremental costs of these technical changes. For example, before choosing between sinters and pellets, engineers considered the tradeoff between increased material costs and reduced environmental costs. Their accounting systems however, did not track the environmental component of incremental costs after switching to pellets. 
When asked about the types of decisions likely to be compromised by hidden costs, most managers initially replied that it was not a major problem because these costs are eventually captured in the total cost of production. However, further discussions revealed that hidden costs can adversely affect responsibility accounting for cost variances, pricing contracts, product profitability analyses, and plant-closure and investment decisions.

Determining responsibility for cost variances: Many steel plants use a standard costing system that compares actual performance to standard or budgeted performance. Plant managers are typically held responsible for material, labor, and overhead variances but not for environmental costs. Hidden environmental costs distort the standard costing system. Consider an integrated steel mill with a production of 20,000 ShT per week and visible costs of environmental regulation of $\$ 12.50$ per ShT - that is, a total visible environmental cost of $\$ 250,000 /$ week. Suppose environmental regulatory stringency as measured by the visible costs of regulation increases by $\$ 1$ per ShT. The total increase in cost after considering hidden costs will be $\$ 9.23$ per ShT., or $\$ 184,600$. However, only $\$ 1$ per ShT., or $\$ 20,000$, will be visible as environmental cost, the remaining \$164,600 will appear as unfavorable materials, labor, and overhead variances. The plant manager will be held responsible for these variances. If the increase in regulatory stringency falls outside the plant manager's control, this distorts the responsibility accounting systems.

Pricing contracts: Long-term supply contracts often include adjustment clauses for unforeseen cost increases arising from regulatory changes. If the internal costing systems report only the directly traceable visible costs, hidden costs arising from changes in regulations will be attributed to other causes including operating inefficiency. As a result, the firm may be 
disadvantaged in price negotiations. In our interviews, the vice president and controller of a large integrated steel firm mentioned that even though costs were increasing rapidly, the firm was unable to negotiate price increases with customers during the 1980 s, because customers attributed these cost increases mainly to inefficient operations.

Product profitability analysis: The managers agreed that the stringency of environmental regulations and associated costs vary across products. Thus, hidden costs also differ across products; consequently, products with smaller hidden costs subsidize by products with greater hidden costs.

Plant closure decisions: Managers indicated that a major tradeoff in determining whether to shut down an older steel mill is the costs of bringing the plant into environmental compliance so that it can continue to operate and generate cash flow versus the cost of pensions if the plant were shut down. If large hidden costs are associated with environmental compliance, and yet managers make these decisions based on only the visible costs of compliance, some mills that should have closed would continue to operate. Managers recalled several steel mills that spent large amounts to come into compliance, only to discover that they could not break-even and hence subsequently closed. Hidden costs of regulations may have played a role in these apparently dysfunctional decisions.

Investment decisions: Current costing systems are likely to under-estimate cost savings from pollution prevention projects. Managers who overlook savings in hidden costs from these investments are likely to under-invest in such projects. 
Managers also need data on full costs of regulation to negotiate with regulators. Without accurate internal data on the total cost of regulations, firms accept regulatory agencies' cost estimates, which may understate costs and result in excessively stringent regulations.

\section{DISCUSSION AND CONCLUSIONS}

This paper empirically examines the extent to which accounting systems reveal the cost of complying with environmental regulation. We draw on production theory and flexible functional form cost estimation to gain insight into the total cost of environmental regulations. Analysis of the U.S. steel industry indicates that accounting systems separately identify only a small portion of the costs of regulatory compliance. A $\$ 1$ increase in the visible costs of regulation is associated with a $\$ 9.23$ increase in total cost (at the margin) for the integrated mill sector and $\$ 10.68$ for the mini-mill sector. These results suggest that an increase in regulatory stringency would significantly increase product costs. The associated hidden costs of regulation are eight to ten times the visible costs at the margin.

Why have steel firm managers not attempted to estimate and include all the environmental costs in the reported costs, when firms have strong incentives to classify costs of regulation, to support claims that they are over-regulated? Our interviews reveal that managers are aware of these hidden costs. However, they often find it difficult to isolate and measure these hidden environmental cost components. Most steel firms still use traditional cost accounting systems with only a few cost pools; obtaining more detailed estimates of environmental costs would require a major change in the cost accounting systems. Some managers believe that collecting such detailed data on all regulatory costs does not pass a subjective cost-benefit test because these costs are captured under other cost categories, so total cost of production is not 
misstated. However, with marginal hidden costs eight to nine times the magnitude of visible costs, a more detailed environmental accounting system may generate materially different accounting numbers that affect decisions. However, managers did not appear to have conducted quantitative cost-benefit tests, consistent with Foster and Young's (1997) conclusion that few firms attempt to quantify the expected benefits of updating their management accounting systems. Our results suggest that investing in more detailed environmental costing systems may be justified, at least in the steel industry.

The statistical model enables managers to estimate hidden regulatory costs and to make quantitative judgments about the benefits of developing more detailed costing systems. However, this study has several limitations. First, the estimates measure hidden costs at the margin. We do not estimate the average level of hidden cost, which is likely to be lower than marginal cost. Second, the estimated hidden costs are based on a statistical association between the variation in total costs and variations in the reported visible environmental costs, which does not establish causality. If firms systematically bundle environmental expenditures with expenses that either increase total cost (by improving safety or quality) or reduce total cost (through productivity improvements), the hidden cost estimates will be biased. Third, the model is based on contemporaneous variations in total and regulatory costs, and does not incorporate learning effects that may reduce hidden costs in subsequent periods. Fourth, the cost of regulation ideally is the shadow price associated with a physical constraint imposed by regulation. We use regulatory expenditures as a single comprehensive proxy for a complex set of emission limits and standards. Finally, environmental costs may also lead to hidden benefits, such as improved 
quality, increased consumer appeal, and lower contingent liabilities, which our estimations do not capture.

Although we do not offer specific guidelines for setting up costing systems that track and help manage these hidden costs, recent reports by the USEPA (USEPA 1995; White et al. 1995) and the IMA (1996) provide an introduction to key concepts and techniques for developing environmental accounting systems.

In conclusion, environmental regulations are likely to play an increasingly important role in modern business. The scope and number of local, federal, and international regulations are rising, imposing significant costs on business. For example, USITC (1991) estimates that expenditures by U.S. steel producers to meet the requirements of the 1990 amendments to the Clean Air Act could add $\$ 17$ per ton of raw steel, or more than 5 percent of the cost of production. Recognition of environmental regulation as an important cost driver, and formal incorporation of regulatory impacts in firms' accounting systems may be imperative for effective decision making. Further, regulators need to know the full costs of regulation to determine the best mix of regulation to benefit society as a whole. 


\section{Appendix}

\section{SURVEY OF POLLUTION ABATEMENT COSTS AND EXPENDITURES (PACE)}

This survey provides comprehensive data on pollution abatement capital expenditures, operating costs, and costs recovered by private industry. The United States Code, Title 13, authorized this survey, and required firms to respond and to certify that the response is substantially accurate.

The Bureau of the Census conducted PACE surveys annually from 1973 to 1993, except during the year 1987. Reported data are for activity during the survey calendar year. The respondents include most large mining firms, selected utility (electric and gas) and petroleum companies, and a sample of manufacturing establishments. The sampling universe for the manufacturing sector covers all manufacturing establishments with at least 20 employees. The PACE reports were based on a mail-out/mail-back survey of about 17,000 manufacturing establishments, and a supplemental survey of 500 mining, petroleum, and utility establishments. Manufacturing establishments were selected from a panel of participants in the Census of Manufactures using a stratified probability procedure. Probability of selection is proportionate to the establishment's census value of shipments. New plants were added each year based on records from the Internal Revenue Service.

The format of the PACE survey has changed over the years, but the common data elements were as follows:

1. Annual operating costs for pollution abatement, including:
a. Depreciation
b. Labor
c. Materials
d. Supplies
e. Fuel
f. Electricity
g. Services
h. Equipment leasing
i. Other costs

2. Total payments to governmental (Federal, State, county, local) units for

a. Public sewage services

b. Municipal solid waste disposal

3. Total expenditures for new plant and equipment designed to abate air pollutants through endof-line techniques.

4. Total expenditures for changes in production process to abate air pollutants. 
5. Total expenditures for new plant and equipment designed to abate water pollutants through end-of-line techniques.

6. Total expenditures for changes in production process to abate water pollutants.

7. Total expenditures for new plant and equipment designed to abate solid waste pollutants through end-of-line techniques.

8. Total expenditures for changes in production process to abate solid waste pollutants.

9. Estimates of total expenditures to abate following pollutants by type of pollutant:
a. Particulate
b. Sulfur oxide
c. Nitrogen oxide
d. Hydrocarbons
e. Lead
f. Hazardous air pollutants
g. Other pollutants

Source: U.S. Bureau of the Census information and the PACE survey form MA-200. 


\section{References}

Banker, R. D. and H. Johnston. 1993. An empirical study of cost drivers in the U.S. airline industry. The Accounting Review 68 (3): 576-601.

Barbera, A. J., and V. D. McConnell. 1990. The impact of environmental regulations on industry productivity: Direct and indirect effects. Journal of Environmental Economics and Management 18 ( ):50-65.

Barth, M. E., and M. F. McNichols. 1994. Estimation and market valuation of environmental liabilities relating to superfund sites. Journal of Accounting Research 32 (supplement): 177209.

Berndt, E. R. 1996. The Practice of Econometrics: Classic and Contemporary. Reading, MA: Addison-Wesley.

Blacconiere, W. G., and W. D. Northcut, 1997 Environmental information and market reactions to environmental legislation. Journal of Accounting, Auditing \& Finance 12 (2): 149-178.

Blacconiere, W.G., and D.M. Patten. 1994. Environmental disclosures, regulatory costs, and changes in firm value. Journal of Accounting and Economics 18 (3): 357-377.

Byron, R. P., and A. K. Bera. 1983. Least squares approximations to unknown regression functions: A comment. International Economic Review 24 (1): 255-260.

Christensen, L. R., and W. H. Greene. 1976. Economies of scale in U.S. electric power generation. Journal of Political Economy 84 (4): 655-676.

Christensen, L. R., and D. W. Jorgenson. 1969. The measurement of U.S. real capital input, 1929-1967. Review of Income and Wealth 15 (December): 293-320.

Christensen, L. R., D. W. Jorgenson, and L. Lau. 1973. Transcedental logarithemic production frontiers. Review of Economics and Statistics 55 (February): 28-45.

Diewart, W. E. 1974. Applications of duality theory. In Frontiers in Quantitative Economics, Volume 2, ed. M. Intrigillator and D. Kendrik, Amsterdam: North-Holland, pp: 106-171.

Ditz, D., J. Ranganathan, and R.D. Banks. 1995. Green Ledgers: Case studies in corporate environmental accounting. Washington D.C.: World Resource Institute.

Dorfman, M., M. Warren, and C. Miller. 1992. Environmental Dividends: Cutting More Chemical Wastes. New York, NY: Inform. 
Environmental Protection Agency, Sector Notebook Project. 1995. Profile of the Iron and Steel Industry. EPA study \# 310-R-95-005.

Epstein, M. 1996. Measuring Corporate Environmental Performance. Montvale, NJ: Institute of Management Accountants.

Foster, G., and S. M. Young. 1997. Frontiers of management accounting research. Journal of Management Accounting Research 9: 63-77.

Gray, W. B. 1987. The cost of regulation: OSHA, EPA and the productivity slowdown. American Economic Review 77(5): 998-1006.

Gray, W. B. and R. J. Shadbegian. 1993. Environmental Regulation and Manufacturing Productivity Growth at the Plant Level. Discussion paper, U.S. Department of Commerce, Center for Economic Studies, Washington, D.C.

Greene, W. H. 1993. Econometric Analysis. 2nd ed. New York, NY: Macmillan.

Guilkey, D. K., C. A. K. Lovell, and R. C.Sickles. 1983. A comparison of the performance of three flexible functional forms. International Economic Review 24 (3): 591-616.

Hall, R. E., and D. W. Jorgenson. 1967. Tax policy and investment behavior. American Economic Review 57(3): 391-414.

Hughes, K. E. 2000. The value relevance of nonfinancial measures of air pollution in the electric utility industry. The Accounting Review 75 (2): 209-228.

Hulten, C. R., and F. C. Wykoff. 1981. The measurement of economic depreciation. In Depreciation, Inflation, and the Taxation of Income from Capital, ed. C.R. Hulten. Washington, D.C.: The Urban Institute Press, pp: 81-125.

Institute of Management Accountants (IMA): Statement 4Z. 1996. Tools and Techniques of Environmental Accounting for Business Decisions. Montvale, NJ: Institute of Management Accountants.

Jaffe, A. B., S. R. Peterson, P. R. Portney, and R. N. Stavins. 1995. Environmental regulation and the competitiveness of U.S. manufacturing: What does the evidence tell us? Journal of Economic Literature 33 (1): 132-163.

Jorgenson D. W., and R. Landau. 1993. Tax Reform and the Cost of Capital: An International Comparison. Washington, D.C.: Brookings Institution.

Jorgenson, D. W., and P. J. Wilcoxen. 1990. Environmental regulation and U.S. economic growth. Rand Journal of Economics 21(2): 314-320. 
Jorgenson D. W., and K. Yun. 1991. Tax Reform and the Cost of Capital. Oxford, U.K.: Claredon Press.

Landy, M. K., M. J. Roberts, and S. R. Thomas. 1990. The Environmental Protection Agency: Asking the Wrong Questions. New York, NY: Oxford University Press.

Lanen, W.N., and D.F.Larcker. 1992. Executive compensation contract: Adoption in the electric utility industry. Journal of Accounting Research 30 (1): 70-93.

Porter, M. E. 1991. America's green strategy. Scientific American 264 (4): 168.

Price Waterhouse LLP. 1994. Progress on the Environmental Challenge: A Survey of Corporate America's Environmental Accounting and Management.

Shephard, R.W. 1970. The Theory of Cost and Production Functions. Princeton, N.J: Princeton University Press.

U.S. Environmental Protection Agency. 1995. An Introduction to Environmental Accounting as a Business Management Tool: Key Concepts and Terms. Office of Pollution Prevention and Toxics, June. Report no. EPA 742-R-95-001.

U.S. International Trade Commission (USITC). 1991. Steel Industry Annual Report on Competitive Conditions in the Steel Industry and Industry Efforts to Adjust and Modernize. Report to the President, Investigation No. 332-289. Washington, D.C.

U.S. International Trade Commission (USITC). 1994. Metallurgical Coke: Baseline Analysis of the U.S. Industry and Imports. Investigation No. 332-342. Washington, DC.

Varian, H.F. 1992. Microeconomic Analysis. 3rd ed. New York, NY: Norton.

White, A. L., D. E. Savage, J. Brody, D. Cavander, and L. Lach. 1995. Environmental Cost Accounting for Capital Budgeting: A Benchmark Survey of Management Accountants. U.S. Environmental Protection Agency, Report no. EPA742-R-95-005. 
Table 1

Reported Costs of Environmental Regulation in the U.S. Steel Industry (in \$/Short Ton)

\begin{tabular}{|c|c|c|c|c|c|c|c|c|}
\hline Year & $\begin{array}{c}\text { Depreciation } \\
\text { Expense }\end{array}$ & $\begin{array}{c}\text { Labor } \\
\text { Expense }\end{array}$ & $\begin{array}{c}\text { Materials } \\
\text { Expense }\end{array}$ & $\begin{array}{c}\text { Services } \\
\text { Expense }\end{array}$ & $\begin{array}{c}\text { Total } \\
\text { Operating } \\
\text { Costs }\end{array}$ & $\begin{array}{c}\text { Capital } \\
\text { Costs }\end{array}$ & $\begin{array}{c}\text { Total Reported } \\
\text { Cost Per Short } \\
\text { Ton Produced }\end{array}$ & $\begin{array}{c}\text { Total Reported } \\
\text { Cost Per Short } \\
\text { Ton of Capacity }\end{array}$ \\
\hline 1975 & 1.11 & 1.10 & 0.13 & 2.61 & 4.95 & 5.14 & 10.09 & 7.68 \\
\hline 1976 & 1.22 & 1.20 & 0.09 & 3.26 & 5.77 & 5.04 & 10.81 & 8.75 \\
\hline 1977 & 1.51 & 1.44 & 0.09 & 4.07 & 7.10 & 5.42 & 12.52 & 9.82 \\
\hline 1978 & 1.71 & 1.64 & 0.28 & 4.15 & 7.78 & 5.01 & 12.79 & 11.10 \\
\hline 1979 & 2.01 & 1.87 & 2.32 & 3.20 & 9.40 & 5.93 & 15.33 & 13.45 \\
\hline 1980 & 2.79 & 2.61 & 3.36 & 3.82 & 12.58 & 6.36 & 18.94 & 13.78 \\
\hline 1981 & 2.79 & 2.66 & 3.19 & 4.42 & 13.06 & 5.12 & 18.18 & 14.23 \\
\hline 1982 & 3.76 & 2.73 & 3.20 & 4.15 & 13.84 & 4.17 & 18.01 & 8.71 \\
\hline 1983 & 3.22 & 2.15 & 3.42 & 3.73 & 12.52 & 1.95 & 14.47 & 8.13 \\
\hline 1984 & 2.42 & 1.78 & 3.91 & 2.22 & 10.33 & 1.18 & 11.50 & 7.87 \\
\hline 1985 & 2.73 & 1.92 & 4.35 & 2.65 & 11.65 & 1.59 & 13.24 & 8.75 \\
\hline 1986 & 2.69 & 1.73 & 4.02 & 2.26 & 10.70 & 0.97 & 11.67 & 7.44 \\
\hline 1988 & 1.36 & 1.46 & 3.34 & 2.02 & 8.19 & 0.67 & 8.86 & 7.04 \\
\hline 1989 & 1.41 & 1.55 & 3.95 & 2.75 & 9.66 & 1.72 & 11.38 & 10.15 \\
\hline
\end{tabular}

Source: PACE Surveys (1975-1989). 
Table 2

Estimated Hidden Costs for Integrated Mills

Model

Cost Function

$$
\begin{aligned}
& C=\exp \left(\beta_{0}+\sum_{i} \beta_{i} \ln P_{i}+\beta_{Y} \ln Y+\beta_{T} T+\beta_{R} \ln R+\underset{i}{2} \sum_{i j} \sum_{\gamma_{i j}} \ln P_{i} \ln P_{j}+\sum_{i} \sum_{i Y} \ln P_{i} \ln Y+\sum_{\gamma_{i T}} \ln P_{i} T+\sum_{\gamma_{i R}} \ln P_{i} \ln R+\frac{1}{\gamma} \gamma_{Y Y}(\ln Y)^{2}\right. \\
& \left.+\gamma_{Y T} \ln Y T+\gamma_{Y R} \ln Y \ln R+\frac{1}{2} \gamma_{T T} T^{2}+\gamma_{T R} T \ln R+\frac{1}{2} \gamma_{R R}(\ln R)^{2}\right)
\end{aligned}
$$

$\underline{\text { Cost Share Equations }}$

$$
\begin{aligned}
& S_{L}=\beta_{L}+\sum_{j} \gamma_{L j} \ln P_{j}+\gamma_{L Y} \ln Y+\gamma_{L T} T+\gamma_{L R} \ln R \\
& S_{M}=\beta_{M}+\sum_{j} \gamma_{M j} \ln P_{j}+\gamma_{M Y} \ln Y+\gamma_{M T} T+\gamma_{M R} \ln R \\
& S_{E}=\beta_{E}+\sum_{j} \gamma_{E j} \ln P_{j}+\gamma_{E Y} \ln Y+\gamma_{E T} T+\gamma_{E R} \ln R \\
& S_{K}=\beta_{K}+\sum_{j} \gamma_{K j} \ln P_{j}+\gamma_{K Y} \ln Y+\gamma_{K T} T+\gamma_{K R} \ln R
\end{aligned}
$$

\begin{tabular}{|c|c|c|c|c|c|}
\hline Parameter & $\begin{array}{l}\text { Estimated } \\
\text { Value }\end{array}$ & $\begin{array}{l}\text { Standard } \\
\text { Error }\end{array}$ & Parameter & $\begin{array}{c}\text { Estimated } \\
\text { Value }\end{array}$ & $\begin{array}{c}\text { Standard } \\
\text { Error }\end{array}$ \\
\hline Intercept $\left(\beta_{\mathrm{O}}\right)$ & $13.5000 * *$ & 0.0607 & Labor $\times$ Output $\left(\gamma_{\mathrm{LY}}\right)$ & -0.0009 & 0.0090 \\
\hline Labor $\left(\beta_{\mathrm{L}}\right)$ & $0.2979 * *$ & 0.0109 & Material $\times$ Output $\left(\gamma_{M Y}\right)$ & -0.0082 & 0.0127 \\
\hline Materials $\left(\beta_{\mathrm{M}}\right)$ & 0.5097 & 0.0153 & Energy $\times$ Output $\left(\gamma_{\mathrm{EY}}\right)$ & $0.0111 * *$ & 0.0038 \\
\hline Energy $\left(\beta_{\mathrm{E}}\right)$ & $0.0928 * *$ & 0.0045 & Capital $\times$ Output $\left(\gamma_{\mathrm{KY}}\right)$ & -0.0020 & 0.0043 \\
\hline Capital $\left(\beta_{\mathrm{K}}\right)$ & $0.0994 * *$ & 0.0052 & Labor $\times$ Time $\left(\gamma_{\mathrm{LT}}\right)$ & -0.0013 & 0.0034 \\
\hline Output $\left(\beta_{Y}\right)$ & $1.0480 * *$ & 0.0492 & Material $\times$ Time $\left(\gamma_{\mathrm{MT}}\right)$ & -0.0074 & 0.0045 \\
\hline Time $\left(\beta_{\mathrm{T}}\right)$ & 0.0033 & 0.0121 & Energy×Time $\left(\gamma_{\mathrm{ET}}\right)$ & 0.0020 & 0.0014 \\
\hline Regulation $\left(\beta_{R}\right)$ & $0.3853 * *$ & 0.0564 & Capital×Time $\left(\gamma_{\mathrm{KT}}\right)$ & $0.0067 * *$ & 0.0021 \\
\hline Labor×Labor $\left(\gamma_{\mathrm{LL}}\right)$ & $0.0844 * *$ & 0.0222 & Labor $\times$ Regulation $\left(\gamma_{L R}\right)$ & $0.0316 * *$ & 0.0094 \\
\hline Labor $\times$ Material $\left(\gamma_{\mathrm{LM}}\right)$ & 0.0074 & 0.0157 & Material $\times$ Regulation $\left(\gamma_{\mathrm{MR}}\right)$ & $-0.0513 * *$ & 0.0133 \\
\hline Labor×Energy $\left(\gamma_{\mathrm{LE}}\right)$ & $-0.0266 * *$ & 0.0090 & Energy $\times$ Regulation $\left(\gamma_{E R}\right)$ & $0.0101 *$ & 0.0040 \\
\hline Labor $\times$ Capital $\left(\gamma_{\text {LK }}\right)$ & -0.0065 & 0.0149 & Capital $\times$ Regulation $\left(\gamma_{\mathrm{KR}}\right)$ & $0.0096 * *$ & 0.0045 \\
\hline Material $\times$ Material $\left(\gamma_{\mathrm{MM}}\right)$ & -0.0020 & 0.0220 & Output $\times$ Output $\left(\gamma_{Y Y}\right)$ & $0.1524 *$ & 0.0647 \\
\hline Material×Energy $\left(\gamma_{\mathrm{ME}}\right)$ & $0.0237 * *$ & 0.0063 & Output $\times$ Time $\left(\gamma_{\mathrm{YT}}\right)$ & -0.0053 & 0.0106 \\
\hline Material $\times$ Capital $\left(\gamma_{\mathrm{MK}}\right)$ & -0.0109 & 0.0075 & Output $\times$ Regulation $\left(\gamma_{\mathrm{YR}}\right)$ & $0.1555 * *$ & 0.0423 \\
\hline Energy $\times$ Energy $\left(\gamma_{\mathrm{EE}}\right)$ & -0.0089 & 0.0067 & Time $\times$ Time $\left(\gamma_{\mathrm{TT}}\right)$ & 0.0164 & 0.0086 \\
\hline Energy $\times$ Capital $\left(\gamma_{\mathrm{EK}}\right)$ & 0.0119 & 0.0075 & Time $\times$ Regulation $\left(\gamma_{\mathrm{TR}}\right)$ & 0.0091 & 0.0113 \\
\hline Capital $\times$ Capital $\left(\gamma_{\mathrm{KK}}\right)$ & $0.0643 * *$ & 0.0173 & Regulation $\times$ Regulation $\left(\gamma_{R R}\right)$ & 0.0577 & 0.0471 \\
\hline
\end{tabular}

Cost Function Parameter Estimates for Integrated Mills (n=94)

Total degrees of freedom $=(m t-k)$ where $m=$ number of equations, $t=$ number of observations, and $k=$ number of parameters to be estimated $=(4 \times 94-28)=348$. (See footnote 16 for details.)

Years covered by the data $=1979,1980,1981,1985,1988$.

Log-likelihood = 490.92; Log-likelihood = 36.21 (when $\beta=0)$.

$\mathrm{R}^{2}$ (Total Cost Function) $=0.89 ; \mathrm{R}^{2}($ Labor Cost Function $)=0.20 ; \mathrm{R}^{2}$ (Material Cost Function $)=0.08$;

$\mathrm{R}^{2}$ (Energy Cost Function) $=0.11$.

$*$ significant at $\alpha=0.05 * *$ significant at $\alpha=0.01$.

Parameter estimates related to regulation are indicated in bold. 
Table 3

Model

Estimated Hidden Costs for Mini-Mills

Cost Function

$$
\begin{aligned}
& C=\exp \left(\beta_{0}+\sum_{i} \beta_{i} \ln P_{i}+\beta_{Y} \ln Y+\beta_{T} T+\beta_{R} \ln R+\frac{1}{2} \sum_{i} \sum_{j} \gamma_{i j} \ln P_{i} \ln P_{j}+\sum_{i} \gamma_{i Y} \ln P_{i} \ln Y+\sum_{i} \gamma_{i T} \ln P_{i} T+\sum_{i} \gamma_{i R} \ln P_{i} \ln R+\frac{1}{2} \gamma_{Y Y}(\ln Y)^{2}\right. \\
& \left.+\gamma_{Y T} \ln Y T+\gamma_{Y R} \ln Y \ln R+\frac{1}{2} \gamma_{T T} T^{2}+\gamma_{T R} T \ln R+\frac{1}{2} \gamma_{R R}(\ln R)^{2}\right)
\end{aligned}
$$

Cost Share Equations

$$
\begin{aligned}
& S_{L}=\beta_{L}+\sum_{j} \gamma_{L j} \ln P_{j}+\gamma_{L Y} \ln Y+\gamma_{L T} T+\gamma_{L R} \ln R \\
& S_{M}=\beta_{M}+\sum_{j} \gamma_{M j} \ln P_{j}+\gamma_{M Y} \ln Y+\gamma_{M T} T+\gamma_{M R} \ln R \\
& S_{E}=\beta_{E}+\sum_{j} \gamma_{E j} \ln P_{j}+\gamma_{E Y} \ln Y+\gamma_{E T} T+\gamma_{E R} \ln R \\
& S_{K}=\beta_{K}+\sum_{j} \gamma_{K j} \ln P_{j}+\gamma_{K Y} \ln Y+\gamma_{K T} T+\gamma_{K R} \ln R
\end{aligned}
$$

\begin{tabular}{|c|c|c|c|c|c|}
\hline Parameter & $\begin{array}{l}\text { Estimated } \\
\text { Value }\end{array}$ & $\begin{array}{l}\text { Standard } \\
\text { Error }\end{array}$ & Parameter & $\begin{array}{l}\text { Estimated } \\
\text { Value }\end{array}$ & $\begin{array}{c}\text { Standard } \\
\text { Error }\end{array}$ \\
\hline $\begin{array}{l}\text { Intercept }\left(\beta_{\mathrm{O}}\right) \\
\text { Labor }\left(\beta_{\mathrm{L}}\right) \\
\text { Materials }\left(\beta_{\mathrm{M}}\right) \\
\text { Energy }\left(\beta_{\mathrm{E}}\right) \\
\text { Capital }\left(\beta_{\mathrm{K}}\right) \\
\text { Output }\left(\beta_{\mathrm{Y}}\right) \\
\text { Time }\left(\beta_{\mathrm{T}}\right) \\
\text { Regulation }\left(\beta_{\mathrm{R}}\right) \\
\text { Labor } \times \text { Labor }\left(\gamma_{\mathrm{LL}}\right) \\
\text { Labor } \times \text { Material }\left(\gamma_{\mathrm{LM}}\right) \\
\text { Labor } \times \text { Energy }\left(\gamma_{\mathrm{LE}}\right) \\
\text { Labor } \times \text { Capital }\left(\gamma_{\mathrm{LK}}\right) \\
\text { Material } \times \text { Material }\left(\gamma_{\mathrm{MM}}\right) \\
\text { Material } \times \text { Energy }\left(\gamma_{\mathrm{ME}}\right) \\
\text { Material } \times \text { Capital }\left(\gamma_{\mathrm{MK}}\right) \\
\text { Energy } \times \text { Energy }\left(\gamma_{\mathrm{EE}}\right) \\
\text { Energy } \times \text { Capital }\left(\gamma_{\mathrm{EK}}\right) \\
\text { Capital } \times \text { Capital }\left(\gamma_{\mathrm{KK}}\right)\end{array}$ & $\begin{array}{c}12.4020^{* *} \\
0.3225 * * \\
0.4936 * * \\
0.1116^{* *} \\
0.0722^{* *} \\
0.8275^{* *} \\
-0.0159 \\
\mathbf{0 . 3 7 8 9} * * \\
0.0621 * * \\
0.0118 \\
-0.0425 * * \\
-0.0314 * * \\
0.0491 * \\
-0.0333 * * \\
-0.0277 * * \\
0.0541 * * \\
0.0216^{*} \\
0.0375 * *\end{array}$ & $\begin{array}{l}0.0479 \\
0.0095 \\
0.0119 \\
0.0035 \\
0.0034 \\
0.0321 \\
0.0085 \\
\mathbf{0 . 0 4 6 8} \\
0.0193 \\
0.0178 \\
0.0095 \\
0.0106 \\
0.0222 \\
0.0063 \\
0.0065 \\
0.0109 \\
0.0092 \\
0.0136\end{array}$ & $\begin{array}{l}\text { Labor } \times \text { Output }\left(\gamma_{\mathrm{LY}}\right) \\
\text { Material } \times \text { Output }\left(\gamma_{\mathrm{MY}}\right) \\
\text { Energy } \times \text { Output }\left(\gamma_{\mathrm{EY}}\right) \\
\text { Capital } \times \text { Output }\left(\gamma_{\mathrm{KY}}\right) \\
\text { Labor } \times \text { Time }\left(\gamma_{\mathrm{LT}}\right) \\
\text { Material } \times \text { Time }\left(\gamma_{\mathrm{MT}}\right) \\
\text { Energy } \times \text { Time }\left(\gamma_{\mathrm{ET}}\right) \\
\text { Capital } \times \text { Time }\left(\gamma_{\mathrm{KT}}\right) \\
\text { Labor } \times \operatorname{Regulation}\left(\gamma_{\mathrm{LR}}\right) \\
\text { Material } \times \text { Regulation }\left(\gamma_{\mathrm{MR}}\right) \\
\text { Energy } \times \text { Regulation }\left(\gamma_{\mathrm{ER}}\right) \\
\text { Capital } \times \operatorname{Regulation}\left(\gamma_{\mathrm{KR}}\right) \\
\text { Output } \times \text { Output }\left(\gamma_{\mathrm{YY}}\right) \\
\text { Output } \times \text { Time }\left(\gamma_{\mathrm{YT}}\right) \\
\text { Output } \times \operatorname{Regulation~}\left(\gamma_{\mathrm{YR}}\right) \\
\text { Time } \times \text { Time }\left(\gamma_{\mathrm{TT}}\right) \\
\text { Time } \times \operatorname{Regulation}\left(\gamma_{\mathrm{TR}}\right) \\
\text { Regulation } \times \operatorname{Regulation}\left(\gamma_{\mathrm{RR}}\right)\end{array}$ & $\begin{array}{c}0.0209 * \\
-0.0290^{*} * \\
0.0122 * * \\
0.0203 * * \\
-0.0016 \\
0.0009 \\
-0.0026^{*} \\
0.0034 * * \\
\mathbf{0 . 0 0 5 7} \\
\mathbf{0 . 0 0 1 8} \\
\mathbf{- 0 . 0 0 3 3} \\
\mathbf{- 0 . 0 0 4 2} \\
-0.2020 * * \\
0.0052 \\
\mathbf{0 . 1 6 2 2} * * \\
-0.0011 \\
-\mathbf{0 . 0 1 1 1} \\
\mathbf{0 . 1 6 1 4} * *\end{array}$ & $\begin{array}{l}0.0083 \\
0.0102 \\
0.0036 \\
0.0034 \\
0.0028 \\
0.0034 \\
0.0012 \\
0.0014 \\
\mathbf{0 . 0 1 1 1} \\
\mathbf{0 . 0 1 4 0} \\
\mathbf{0 . 0 0 3 9} \\
\mathbf{0 . 0 0 4 0} \\
0.0479 \\
0.0072 \\
\mathbf{0 . 0 3 4 4} \\
0.0057 \\
\mathbf{0 . 0 1 2 0} \\
\mathbf{0 . 0 3 2 9}\end{array}$ \\
\hline
\end{tabular}

Cost Function Parameter Estimates for Mini-Mills $(n=109)$

Total degrees of freedom $=(m t-k)$ where $m=$ number of equations, $t=$ number of observations, and $k=$ number of parameters to be estimated $=(4 \times 109-28)=408$. (See footnote 16 for details. $)$

Years covered by the data $=1979,1980,1981,1985,1988$.

Log-likelihood = 614.54; Log-likelihood = 10.41 (When $\beta=0)$.

$\mathrm{R}^{2}($ Total Cost Function $)=0.95 ; \mathrm{R}^{2}($ Labor Cost Function $)=0.23 ; \mathrm{R}^{2}$ (Material Cost Function $)=0.04$;

$\mathrm{R}^{2}$ (Energy Cost Function) $=0.49$.

* significant at $\alpha=0.05 ; \quad * *$ significant at $\alpha=0.01$.

Parameter estimates related to regulation are indicated in bold. 
Table 4

Estimated Effect of Regulation on Total Cost and Hidden Costs

\begin{tabular}{|c|c|c|}
\hline & Integrated Mills & Mini-mills \\
\hline Mean cost of production $(\$ / \mathrm{ShT})$ & 360 & 340 \\
\hline $\begin{array}{l}\text { Visible cost of environmental regulation } \\
(\$ / \text { ShT })\end{array}$ & 12 & 9 \\
\hline $\begin{array}{l}\text { Elasticity of total cost with respect to } \\
\text { regulation, } \partial \ln C / \partial \ln R \text { (standard errors in } \\
\text { parentheses) }\end{array}$ & $\begin{array}{c}0.3079 \\
(0.0416)\end{array}$ & $\begin{array}{c}0.2827 \\
(0.0376)\end{array}$ \\
\hline $\begin{array}{l}\text { Increase in total cost/ShT for } \$ 1 / \mathrm{ShT} \\
\text { increase in visible cost of environmental } \\
\text { regulation }{ }^{\mathrm{b}}\end{array}$ & 9.23 & 10.68 \\
\hline $\begin{array}{l}\text { Hidden regulatory cost at the margin per } \\
\text { ShT for } \$ 1 / \text { ShT increase in visible cost }\end{array}$ & 8.23 & 9.68 \\
\hline
\end{tabular}

a. We calculate the regulatory elasticity using the coefficient estimates reported in Tables 2 and 3 and equation (11) as follows:

Integrated Mills: $\partial \ln C / \partial \ln R=0.3853+0.0316 * \ln \mathrm{P}_{\mathrm{L}}-0.0513 * \ln \mathrm{P}_{\mathrm{M}}+0.0101 * \ln \mathrm{P}_{\mathrm{E}}$ $+0.0096 * \ln \mathrm{P}_{\mathrm{K}}+0.1555^{*} \ln \mathrm{Y}+0.0091 \mathrm{~T}+0.0577 \ln \mathrm{R}$.

Mini-mills: $\partial \ln C / \partial \ln R=0.3789+0.0057 * \ln \mathrm{P}_{\mathrm{L}}+0.0018 * \ln \mathrm{P}_{\mathrm{M}}-0.0033 * \ln \mathrm{P}_{\mathrm{E}}-$ $0.0042 * \ln \mathrm{P}_{\mathrm{K}}+0.1622 * \ln \mathrm{Y}-0.0111 \mathrm{~T}+0.1614 \ln R$.

We use the mean values of $\ln \mathrm{P}_{\mathrm{L}}, \ln \mathrm{P}_{\mathrm{M}}, \ln \mathrm{P}_{\mathrm{E}}, \ln \mathrm{P}_{\mathrm{K}}, \ln \mathrm{Y}$, and $\operatorname{lnR}$ in the calculations.

b. A $\$ 1$ per ShT increase in regulatory cost amounts to an increase of 8.33 percent of the visible regulatory costs for integrated mills $(1 / 12=0.0833)$ and 11.11 percent of the visible regulatory costs for mini-mills $(1 / 9=0.1111)$. Increase in total cost is calculated as (mean cost of production per ShT $) \times(\partial \ln C / \partial \ln R) \times($ Proportion of increase in visible cost of regulation); that is, $360 \times 0.3079 \times 0.0833$ (for integrated mills) and $340 \times 0.2827 \times 0.1111$ (for mini-mills). 
Table 5

Estimated Hidden Costs in Major Cost Categories

\begin{tabular}{|c|c|c|}
\hline & Integrated Mills & Mini-Mills \\
\hline $\begin{array}{l}\text { Parameter Estimates }^{\mathrm{a}} \\
\text { Labor } \times \text { Regulation }\left(\gamma_{\mathrm{LR}}\right) \\
\text { Material } \times \text { Regulation }\left(\gamma_{\mathrm{MR}}\right) \\
\text { Energy } \times \text { Regulation }\left(\gamma_{\mathrm{ER}}\right) \\
\text { Capital } \times \text { Regulation }\left(\gamma_{\mathrm{KR}}\right)\end{array}$ & $\begin{array}{r}0.0316 \\
-0.0513 \\
0.0101 \\
0.0096\end{array}$ & $\begin{array}{l}\mathrm{NS}^{\mathrm{b}} \\
\mathrm{NS} \\
\mathrm{NS} \\
\mathrm{NS}\end{array}$ \\
\hline $\begin{array}{c}\text { Average Unit Cost in Dollars (Cost Shares in } \\
\text { parenthesis) } \\
\text { Labor } \\
\text { Material } \\
\text { Energy } \\
\text { Capital } \\
\text { Total Unit Cost }\end{array}$ & $\begin{array}{r}103.68(28.80 \%) \\
200.41(55.67 \%) \\
27.97(7.77 \%) \\
27.94(7.76 \%) \\
360.00\end{array}$ & $\begin{array}{r}103.87(30.55 \%) \\
175.95(51.75 \%) \\
40.66(11.96 \%) \\
19.52(5.74 \%) \\
340.00\end{array}$ \\
\hline $\begin{array}{c}\text { Average Unit Cost in Dollars, after a \$1 per Short } \\
\text { Ton Increase in Regulatory Stringency }{ }^{\text {(Cost }} \\
\text { Shares in parenthesis) } \\
\text { Labor } \\
\text { Material } \\
\text { Energy } \\
\text { Capital } \\
\text { Total Unit Cost } \\
\end{array}$ & $\begin{array}{l}107.26(29.05 \%) \\
204.04(55.26 \%) \\
28.98(7.85 \%) \\
28.95(7.84 \%) \\
369.23\end{array}$ & $\begin{array}{l}107.13(30.55 \%) \\
181.48(51.75 \%) \\
41.94(11.96 \%) \\
20.13(5.74 \%) \\
350.68\end{array}$ \\
\hline $\begin{array}{c}\text { Visible Increase In Regulatory Cost }(\$ / \text { ShT) } \\
\text { Labor } \\
\text { Material } \\
\text { Energy } \\
\text { Capital } \\
\end{array}$ & $\begin{array}{l}0.29 \\
0.55 \\
0.08 \\
0.08\end{array}$ & $\begin{array}{l}0.30 \\
0.52 \\
0.12 \\
0.06\end{array}$ \\
\hline $\begin{array}{l}\text { Hidden Costs }(\$ / \mathbf{S h T})^{\mathrm{e}} \\
\text { Labor } \\
\text { Material } \\
\text { Energy } \\
\text { Capital }\end{array}$ & $\begin{array}{l}3.29 \\
3.08 \\
0.93 \\
0.93\end{array}$ & $\begin{array}{l}2.96 \\
5.01 \\
1.16 \\
0.55\end{array}$ \\
\hline
\end{tabular}

a. From Table 2 for integrated mills and table 3 for mini-mills.

b. Not Significant (NS).

c. Average cost shares in the post-regulatory period after a $\$ 1$ per short ton increase in regulation (see footnote 21 for example calculation).

d. We assume that the visible increase in each cost category is proportional to the original cost shares.

e. Cost in the post-regulatory period -Cost in the pre-regulatory period - Visible costs increase in regulation. For example, hidden labor cost for the integrated mills sector $=107.26-103.68$ $-0.29=3.29$. 
${ }^{1}$ For example, in the 1979 Annual Report, the CEO of U.S. Steel Corporation notes that one of the reasons for the shutdown of some operations was "unrealistic environmental control regulations," and further, that "they certainly played a major cumulative role" in the shutdowns. Competition from low-cost imported steel from Japan and Korea also contributed to the decline.

${ }^{2}$ Hidden costs of regulation can be positive or negative. If regulations increases the cost of production, these hidden costs will be positive. If, however, regulations lead the firm to adopt more efficient production processes, costs of production may decrease. Porter (1991) argues that more stringent environmental regulations motivate firms to re-engineer their production processes and thereby improve overall productive efficiency, empirical research has not found that environmental regulations reduce costs. (Jaffe et al. 1995).

${ }^{3}$ Each company expressed aggregate environmental costs differently (e.g., as a percentage of either manufacturing costs, operating costs, or net sales), based on what managers thought was appropriate for their companies/industries. As the authors acknowledge, these numbers do not allow meaningful comparisons.

${ }^{4}$ Barbera and McConnell (1990) use aggregate industry data for five industries, including the steel industry, to examine the impact of environmental regulation on productivity growth rate. Gray and Shadbegian (1993) analyze the relation between environmental regulations and total factor productivity (TFP) in oil-refining, paper, and steel industries, by regressing the observed TFP and TFP growth rates on various measures of environmental regulation, such as the number of pollution inspections, emission levels, and compliance costs. They conclude that the adverse effect of regulations on TFP is more than is explained by the reported compliance costs. These studies suffer from some of the following limitations: (a) use of industry aggregate data, (b) pooling of data from integrated and mini-mills, each of which employs very different technologies, (c) imposition of constant returns to scale technology, and (d) the assumption that environmental regulation does not change the elasticity of substitution between the various inputs. Our approach addresses all these limitations.

${ }^{5}$ We also scrutinized the $10-\mathrm{K}$ reports filed with the SEC. Only three steel firms, Bethlehem Steel Corporation, Inland Steel Corporation, and USX Corporation, occasionally reported environmental costs in their 10-K reports. The reported environmental operating costs for these companies ranged from \$2.53/ton for Inland steel in 1979 to $\$ 24.25 /$ ton for USX in 1985 . None reported for all the sample years.

${ }^{6}$ Christensen and Greene (1976) and Diewart (1974) discuss the formal properties of cost function and its dual relationship with the production function.

${ }^{7}$ For example, consider a steel mill with a cost of production of $\$ 300 /$ ShT and current visible cost of regulation of $\$ 10 / \mathrm{ShT}$, or 3.33 percent of total cost of production. Suppose an increase in regulatory stringency causes an increase of $\$ 1$ in the visible regulatory 
cost, to $\$ 11$. If no hidden regulatory costs exist then the total cost of production also increases by $\$ 1 / \mathrm{ShT}$, to $\$ 301 / \mathrm{ShT}$. The elasticity of total cost with respect to changes in regulatory restriction is 0.0333 , calculated as percentage change in total cost/ percentage change in visible cost of regulation $([1 / 300] /[1 / 10])$. This is the same as the current proportion of visible cost to the total cost of production. Instead, suppose there are hidden costs of regulation of $\$ 4 / \mathrm{ShT}$. Then the total cost will increase to $\$ 305 / \mathrm{ShT}$, yielding an elasticity of regulation of 0.1667 . $([5 / 300] /[1 / 10]=50 / 300=0.1667)$. Alternatively, $\partial$ $\ln C / \partial \ln R=(\partial C / \partial R)(R / C)$. If $\partial C / \partial R=1$, then $\partial \ln C / \partial \ln R=(R / C)$.

${ }^{8}$ Other major strengths of the translog function are: (a) one may obtain and test simpler functions that exhibit constant returns to scale, input neutral technical change, and so forth, by simple parameter restrictions on the general form, and (b) one may directly calculate elasticities of substitution and conditional factor demand functions from the estimated cost function parameters. Some of the limitations of translog functions are: (a) translog parameter estimates are local Taylor series approximations and hence are most accurate around the expansion point; (b) the estimated cost functions are not guaranteed to satisfy conditions of concavity in input prices and positive cost shares required of proper cost functions, and hence one must test the estimated cost functions for these regularity conditions; and (c) when production technology is very complex or when substitution is very easy or very difficult, inferences on the estimated elasticities are not robust. Refer to Guilkey et al. (1983), Byron and Bera (1983), Jorgenson and Wilcoxen (1990), and Berndt (1996) for further details and applications.

${ }^{9}$ Lanen and Larcker (1992) use the translog cost function to examine whether electric utilities' adoption of compensation contracts is related to the interaction between changes in the regulatory environment and the level of productive efficiency.

${ }^{10}$ These data are not publicly available and were collected while the first author was a Special Sworn Employee at the Center of Economic Studies, U.S. Bureau of the Census. Confidentiality agreements with the U.S. Bureau of the Census prohibit identifying individual firms.

${ }^{11}$ The Annual Survey of Manufacturers is a sample survey conducted every year, whereas the MECS is a sample survey conducted every three years. Hence, data are not available for all mills for all years. However, there was a special annual energy consumption survey during 1975-1981. Census of Manufacturers is conducted once every five years.

${ }^{12}$ Divisia price index is the sum of prices of individual components weighted by their cost shares. For example, if a plant paid \$20/ShT for pellets and \$30/ShT of sinters, and if pellets accounted for 40 percent of material costs and sinters 60 percent, then the divisia price index is $(20 \times 0.4+30 \times 0.6)=\$ 26 /$ ShT . Divisia index is appropriate for input groups that are functionally separable (i.e. inputs within the subgroup are easily substitutable [Varian 1992, 150]). 
${ }^{13}$ Real capital stock in period $t=$ Real capital stock at beginning of period $(\mathrm{t}-1)+$ Real capital stock added in period (t-1) - Real economic depreciation for period ( $\mathrm{t}-1)$. We start the capital stock series in 1972, using the book value of assets in 1972 to minimize the errors in real capital stock estimates due to differences in economic and accounting depreciation rates.

${ }^{14}$ These products are hot rolled sheet and strip (40 percent of total value), hot rolled bars (23 percent), cold rolled sheet and strip (15 percent), ingots and other semi-finished products ( 8 percent), pipes and tubes ( 4 percent), cold finished bars ( 2 percent), rails and heavy structurals ( 2 percent), and steel wire (1 percent). We estimated the quantity of other products using an average industry price.

${ }^{15}$ Such a composite index is appropriate when the relative prices of the components are fixed (Varian 1992, 148) and higher prices arise mainly due to increased processing costs. In steel mills, processes until molten steel making are common to all steel products, and individual product prices reflect higher processing (mostly rolling and coating) costs from that stage. The ratio of prices of various types of steel output relative to hot rolled sheet are fairly constant for the period 1972-1989, with standard deviations of less than $5 \%$.

${ }^{16}$ Because we are estimating a system of equations and imposing cross-equation parameter restrictions, the degrees of freedom available are $=(m t-k)$ where $m=$ number of equations, $t=$ number of observations, and $k=$ number of parameters to be estimated. Hence, the degrees of freedom are 348 for the integrated mills sector, and 408 for the mini-mill sector. Because we dropped the capital share equation, we calculate the eight capital-related parameters listed in Tables 2 and 3 are calculated from other parameter estimates using the constraints in equations (3), (4), and (5).

${ }^{17}$ We calculate the standard error of the regulatory elasticity using the variancecovariance matrix of the estimated coefficients, because $\partial \ln C / \partial \ln R$ is a linear function of estimated coefficients.

${ }^{18}$ Even where there were violations of the concavity conditions, the eigen values of the Hessian matrix were very close to zero $(<0.01)$. Given the computational complexity, we assume that these equal zero and hence satisfy concavity conditions.

${ }^{19}$ We use the gross state product and its growth rate in the state where the plant is located to create an instrumental variable for output.

${ }^{20}$ The standard Durbin-Watson test for serial correlation is not applicable because we estimate a system of equations with cross-equation parameter restrictions, using panel data with some time gaps.

${ }^{21}$ From equation (7), the change in labor cost shares is $\Delta \mathrm{S}_{\mathrm{L}}=\gamma_{\mathrm{LR}} \mathrm{x} \Delta(\operatorname{lnR})$. Therefore, a $\$ 1$ increase in regulatory cost from $\$ 12$ to $\$ 13$ changes the labor cost share by $\gamma_{\mathrm{LR}} \mathrm{X}(\ln 13$ $\ln 12)=0.0316 \times 0.08=0.0025$. The new cost share of labor after the increase in regulatory 
stringency will be $0.288+0.0025=0.2905$ (i.e., 29.05 percent). Similar calculations yielded estimates of changes in other input cost shares.

${ }^{22}$ For example, more stringent coke-oven regulations led to reduction in coke use from 0.65 ton per ton of raw steel produced in 1973 to 0.45 tons/ton in 1994. Similarly, the yield of finished steel products/ton of raw steel produced increased from 70 percent in 1973 to about 90 percent in 1994.

${ }^{23}$ These included one retired chief executive officer, one controller, one controller and vice president, one retired vice president, two managers of financial reporting, and one manager of environmental issues. We also talked to two plant-level accountants. Many of the executives we interviewed, including the CEO, had worked in other steel firms. Their judgment was that other steel firms' environmental accounting systems were similar. Hence our observations are more generally applicable. 